\title{
Desinfectantes para la descontaminación de superficies e instrumental odontológico durante la pandemia del COVID-19
}

\section{Disinfectants for the decontamination of surfaces and dental instruments during the COVID-19 pandemic}

\author{
Alexandra Amaro Collachagua1 (iD), Cesar Bernal Yzaguirre1 (iD), \\ Manuel Antonio Mattos-Vela ${ }^{*}$ \\ ${ }^{1}$ Universidad Nacional Mayor de San Marcos, \\ Facultad de Odontología. Lima, Perú.
}

Autor correspondiente: mmattosv@unmsm.edu.pe

Resumen: Se ha avanzado en el conocimiento de las características y comportamiento del COVID-19, lo cual debe ser aprovechado por los profesionales de la salud a fin de proteger a sus pacientes y a ellos mismos. El objetivo de esta revisión actualizada de la literatura fue informar sobre los desinfectantes que se pueden utilizar para descontaminar superficies e instrumental en la consulta odontológica. Se realizó una exploración electrónica para seleccionar información científica en PubMed a través del NCBI, Biblioteca Virtual en Salud y en bases de datos SciELO, Redalyc, Dialnet, Latindex, Cochrane Library, LILACS y repositorios académicos, la información utilizada comprendió artículos de revisión, artículos originales $\mathrm{y}$ tesis relacionadas con SARS-CoV-2/COVID-19 y desinfectantes durante el periodo enero 2019 a enero 2021, considerando también algunos artículos relevantes sobre desinfección, de años anteriores.

Palabras clave: COVID-19, betacoronavirus, desinfección.

Abstract: Progress has been made in the knowledge of the characteristics and behavior of COVID-19, which should be used by health professionals in order to protect their patients and themselves. The objective of this updated review of the literature was to inform about the disinfectants that can be used to disinfect surfaces and instruments in the dental office. An electronic exploration was carried out to select scientific information 
in PubMed through the NCBI, Virtual Health Library and in databases SciELO, Redalyc, Dialnet, Latindex, Cochrane Library, LILACS and academic repositories, the information used included review articles, original articles and theses related to SARS-CoV-2/COVID-19 and disinfectants during the period January 2019 to January 2021, also considering some relevant articles on disinfection, from previous years.

Keywords: COVID-19, betacoronavirus, disinfection.

\section{INTRODUCCIÓN}

El COVID-19 es una enfermedad respiratoria viral causada por un nuevo coronavirus llamado SARS-CoV-2. La División de Microbiología Clínica de la Universidad de Pittsburgh realizó un análisis genético de 86 genomas completos o casi completos de SARS-CoV-2 y revelaron muchas mutaciones y deleciones en regiones codificantes y no codificantes. Estas observaciones proporcionaron evidencia de la diversidad genética y rápida evolución de este nuevo coronavirus ${ }^{(1)}$.

A nivel mundial, al 03 de junio del 2021, se reportaron un poco más de 171 millones de casos confirmados de infectados, siendo las regiones más afectadas las Américas y Europa(2). Esta enfermedad varía según el tejido que infecte y las características clínicas que presente el paciente antes de la infección ${ }^{(3)}$; siendo, en el ser humano, capaz de replicarse en el interior de las células epiteliales respiratorias. La transmisión se da de persona infectada a otra no infectada a través de gotas de saliva, aire al toser o estornudar, con contacto directo como estrechar manos, o al tocar algún objeto cuya superficie esté contaminada con el virus y luego tocar membranas de nuestro cuerpo(4). La sintomatología que se produce a causa de este virus es similar al de la gripe, entre ellos la fiebre, tos, mialgia, disnea y fatiga. Además, se ha manifestado pérdida súbita del gusto y el olfato. En casos severos puede provocar neumonía, síndrome de dificultad respiratoria aguda, sepsis y choque séptico(5). En este contexto, la atención odontológica presenta riesgos, ya que involucra el uso de elementos rotatorios, de abrasión por aire o de jeringa triple generando una nube de aerosol. Las principales vías de infección en una consulta odontológica son: el contacto directo con los fluidos corporales de un paciente infectado y el contacto con superficies (mascarillas, gafas, etc.) antes, durante y después de los tratamientos dentales. Por ello, los estomatólogos y el personal de salud deben de tomar estrictas medidas de bioseguridad, así como la 
reducción de producción de aerosoles ${ }^{(6)}$. Además, es importante que se mantengan informados y actualizados para evitar posibles complicaciones y la propagación del COVID-19. La presente revisión tiene el objetivo de informar acerca del uso de desinfectantes que se pueden emplear para la descontaminación de superficies y herramientas odontológicas como una medida preventiva contra el COVID-19 durante la atención odontológica.

\section{METODOLOGÍA}

Se realizó una revisión bibliográfica para la selección de información científica en PubMed a través del NCBI, Biblioteca Virtual en Salud y en las bases de datos SciELO, Redalyc, Dialnet, Latindex, Cochrane Library, LILACS y repositorios académicos. La selección de información se basó en artículos de revisión, artículos originales, protocolos y tesis relacionadas con SARSCoV-2/COVID-19 y desinfectantes, en idioma inglés y español, en el periodo enero 2019 a enero 2021, sin embargo, también se recogió información relevante sobre desinfectantes, de años anteriores, observadas en las referencias bibliográficas de los artículos previamente seleccionados.

\section{RESULTADOS Y DISCUSIÓN}

\section{1. ¿Qué es el coronavirus?}

El coronavirus es una amplia familia de virus que pueden transmitirse a través de mamíferos, aves y por algunos animales hacia los humanos. Su material genético tiene un diámetro de $120 \mathrm{~nm}$ y es un ARN monocatenario, siendo esta característica la responsable de la susceptibilidad a la mutación que estos presentan. También son considerados el factor etiológico para el resfriado común y los síndromes respiratorios tales como síndromes respiratorios agudos (SARS-CoV) y síndrome respiratorio del oriente medio (MERS-CoV)(7). El COVID-19 tiene un mecanismo de acción en la que participan las glicoproteínas de espigas, las cuales son indispensables para el ingreso a las células huésped y la S2 adhiriéndose a la membrana celular. El receptor es una enzima convertidora de angiotensina ACE-2, que está ubicada en la membrana celular que se une con la subunidad S1, la serina proteasa transmembrana del hospedero activa la espiga interactuando con la ACE-2, y la serina proteasa transmembrana actúa con la subunidad 2, fusionando la membrana celular con el virus, y así es como permite el ingreso de este a la célula( ${ }^{(8)}$. 


\subsection{Características del SARS-CoV 2}

El SARS-CoV 2 presenta características similares a otros virus, sin embargo, tiene una alta transmisión y niveles de mortalidad, por lo que se considera que existen otros factores que motivan su alta virulencia (Tabla 1$)^{(9)}$.

Tabla 1. Características epidemiológicas, clínicas y biológicas de SARS-CoV 2.

\begin{tabular}{|c|c|}
\hline $\begin{array}{c}\text { Características epidemiológicas, } \\
\text { clínicas y biológicas }\end{array}$ & SARS-CoV 2 \\
\hline Distribución & Pandemia \\
\hline Origen & Wuhan, provincia de Hubei, China \\
\hline Reservorio natural & Murciélago \\
\hline Secuencia viral & $\begin{array}{l}\text { Tiene } 89 \% \text { de similitud con SARS-CoV, } \\
64 \% \text { con } \\
\text { MERS-CoV }\end{array}$ \\
\hline $\begin{array}{l}\text { Otro probable sospechoso intermediario/ } \\
\text { anfitrión }\end{array}$ & ¿Los pangolines? \\
\hline Transmisión & Extensión de persona a persona/otros \\
\hline Patogenicidad (receptor involucrado) & ACE-2 \\
\hline Periodo de incubación & 2-14 días \\
\hline Síntomas principales & $\begin{array}{l}\text { Síntomas similares a la gripe, tos seca, } \\
\text { fiebre, diarrea, dolor de cabeza, malestar } \\
\text { por mialgia, falta de aliento }\end{array}$ \\
\hline Enfermedad letal & Neumonía severa \\
\hline Pacientes con riesgo de muerte o muerte & $\begin{array}{l}\text { Ancianos y personas con condiciones } \\
\text { preexistentes }\end{array}$ \\
\hline Factor R0 & $1,4-5,5$ \\
\hline Tasa de fatalidad de caso & $0,5-3 \%$ \\
\hline Niños & Informado con poca frecuencia \\
\hline
\end{tabular}




\subsection{Agentes desinfectantes}

Alcohol. Los alcoholes (etanol o alcohol etílico, alcohol isopropílico) son compuestos orgánicos del agua, empleados desde antaño en la medicina como antiséptico y desinfectante. Los alcoholes habitualmente utilizados son el etanol y alcohol isopropílico, a una concentración entre 70-96\% y 70$100 \%$, respectivamente. Entre ellos, el etanol es considerado el menos irritante. Su eficacia se basa en su composición de agua, ya que esta le otorga poder de penetración sobre las células causando daño en la membrana y desnaturalizando proteínas; de este modo, altera el metabolismo y se produce lisis celular(10). El alcohol posee la capacidad de destruir la cápside que rodea a algunos virus, entre ellos se encuentra el coronavirus. Posee una acción rápida (desde los 15 segundos) y amplio espectro sobre bacterias, hongos y virus, no sobre esporas. Por ello no se recomienda su uso para esterilización; sin embargo, sí como desinfectante de superficies. Los desinfectantes para manos, con una concentración de $60 \%$ de alcohol, poseen la capacidad de inactivar los virus. El alcohol puede emplearse como desinfectante al $75 \%$ sobre gafas y máscaras protectoras. Para el caso de articuladores y adaptadores de tubos de succión se recomienda exfoliar con alcohol etílico al 70\% después de cada uso(11).

Kampf et al. demostraron la persistencia de coronavirus sobre superficies inanimadas y su inactivación con agentes biocidas, indicando que la acción desinfectante del etanol al $62 \%-71 \%$ se produce en 60 segundos $^{(12)}$.

Hipoclorito de sodio. El hipoclorito de sodio $(\mathrm{NaOCl})$ es una sal formada por la unión del ácido hipocloroso y el hidróxido de sodio. Entre sus características se considera un compuesto hipertónico (2800 m0smol/kg) y muy alcalino, ya que presenta un $\mathrm{pH}$ entre 11,5 a 11,7 . Posee un amplio efecto contra bacterias, esporas, hongos y virus, incluyendo los coronavirus. Su mecanismo de acción se basa en su capacidad de oxidar e hidrolizar las proteínas celulares(13). El $\mathrm{NaOCl}$ deshidrata y solubiliza las proteínas de la capa de envoltura del virus y de este modo propicia su desintegración.

Se debe tener precaución de no mezclarlo con ácidos (vinagre, limón, productos desinfectantes que contengan ácido clorhídrico) ya que se formaría ácido hipocloroso y cloro gaseoso, los cuales son altamente tóxicos. Otra mezcla dañina para el organismo es la del amoniaco con hipoclorito de sodio, esta combinación produce irritación de las mucosas y vías respiratorias ya que se liberan vapores de cloro y cloramina. Se recomienda 
preparar una solución clorada al $0,1 \%$ para el lavado de manos y otra solución clorada al $0,5 \%$ para la limpieza de superficies.

En cuanto a materiales dentales, se recomienda el uso de hipoclorito de sodio al 1\% para el lavado y desinfectado de modelo de yeso, antes de ser utilizado. En pruebas de prótesis dentales de acrílico deben ser sumergidas en hipoclorito de sodio al $1 \%{ }^{(14)}$. Para desinfectar las superficies alrededor de la unidad dental se recomienda emplear una concentración de $0,1 \%$.

Kampf et al.(12), mencionan que la acción desinfectante del hipoclorito de sodio entre el $0,1 \%$ y $0,5 \%$ se genera en 1 minuto.

Glutaraldehído. Es un agente químico relacionado con el formaldehído y es activo en una concentración más baja. Tiene amplio espectro ya que posee un alto nivel desinfectante contra bacterias Gram positivas y Gram negativas, bacilos, hongos y virus. Su efectividad se alcanza a valores de un pH alcalino e inhibe la síntesis de proteínas, ADN y ARN.

Es utilizado como primera acción para la desinfección de instrumental odontológico, se recomienda su uso durante el prelavado con un tiempo de sumersión por 20 minutos $^{(15)}$ y en caso de emplearse como agente esterilizante se debe sumergir el material durante 10 horas. Esta sustancia no corroe los metales y no deteriora fibras ni plásticos, por lo tanto permite esterilizar instrumental delicado(16).

Las pruebas de prótesis dentales pueden ser desinfectadas sumergiéndose con glutaraldehído al 2\%, en caso sean de material metálico. En ortodoncia, se recomienda desinfectar los brackets con glutaraldehído al $2 \%$ antes de su reposición. Además, se puede aplicar esa misma concentración para desinfectar sillones dentales y unidad de servicio dental que hayan sido contaminados con sangre y/o pus(17).

Formaldehído. El formaldehído o formol es un compuesto químico constituido por carbono, hidrógeno y oxígeno. Además, como parte de su metabolismo celular, todas las formas de vida como humanos, animales y plantas lo producen de forma natural. El formol es más conocido por sus propiedades conservadoras que antibacterianas, pero la industria química lo utiliza para hacer una gama amplia de productos. El formol es uno de los compuestos que más se han estudiado y más usos tiene en el mercado(18). Su capacidad para reaccionar le permite interactuar con el grupo amino de proteínas, lo que provoca una coagulación, es debido a esto que se usa como 
curtiente de proteínas, pues favorece el endurecimiento de los tejidos(19). Además, también reacciona con los ácidos nucleicos de los virus, destruyendo así su capacidad de infección, por lo que el genoma del virus de una sola tira queda inactivado más fácilmente que los de doble tira(20).

En contacto con la piel y mucosas puede ocasionar toxicidad local como reacciones alérgicas, por exposición repetida, así como dermatitis y dermatosis, tanto en cara, cuello, y superficies de flexión como párpados y codos donde se produce un intenso edema. Se puede utilizar como desinfectante para el instrumental y superficies inertes, la concentración adecuada para este uso es del $40 \%$, adicionado de metanol a fin de evitar su paso a paraformaldehido(21).

Cloruro de cetilpiridino. Es un compuesto de amonio cuaternario soluble en agua, posee propiedades tensioactivas, y no es oxidante ni corrosivo. Normalmente está indicado como detergente o antiséptico. En su presentación como colutorio posee efectos antibacterianos, antibiopelícula y antigingivitis(22). Estudios in vitro demostraron su efectividad en diferentes cepas de virus de la influenza, cuyo principal mecanismo de acción es alterar la estructura lipídica de la envoltura del virus, inhibiendo la capacidad para ingresar a las células de su hospedero. Como consecuencia, se puede inferir que el cloruro de cetilpiridino (CPC) actúa contra virus con características similares: virus de la parainfluenza, virus sincicial respiratorio (VSR) y SARS-CoV(23). En humanos, se usó una variación inhalatoria de CPC para prevenir cuadros respiratorios asociados a virus VSR, rinovirus, adenovirus y neumonía viral, concluyendo que en los pacientes del grupo experimental con CPC inhalatorio disminuyó la severidad y duración de los cuadros descritos previamente. Ha sido evaluado por la industria farmacéutica como noveno lugar entre 36 productos que pueden inhibir el coronavirus (MERS$\mathrm{CoV})^{(24)}$. La Comisión Nacional de Salud del gobierno chino en su guía para el diagnóstico y tratamiento del COVID-19 indicó que la clorhexidina al 0,12\%, usada como enjuague bucal, en la práctica, no era efectiva para el SARS-CoV2; pues el virus es susceptible a la oxidación, por ello, se sugiere usar peróxido de hidrógeno al $1 \%$ o yodopovidona al $0,2 \%(25)$. Pero según evidencia disponible, resulta pertinente considerar a la povidona yodada como alternativa de enjuague preoperatorio de dosis única y, a su vez, al CPC como uso crónico permanente con el objetivo de disminuir la severidad de COVID-19 mediante la reducción de la carga viral oral en sujetos 
infectados y disminuir la transmisión al limitar la carga viral en gotas de saliva y de aerosoles producidos durante procedimientos dentales(26).

Povidona yodada. Previa a la consulta, es altamente recomendado hacer un enjuague con povidona yodada con a fin de controlar la carga viral del SARSCoV-2 preoperatoria(27). Sin embargo, su preparación es empírica, tiene poca sustantividad, y carece de efecto antigingivitis y antibiopelícula(28). Además, está contraindicada en pacientes que sufran intolerancia al yodo, su uso prolongado debe evitarse porque ocasiona trastornos tiroideos ${ }^{(29)}$.

Como colutorio, su uso está fundamentado por trabajos in vitro de grupos de investigación japoneses y alemanes. El grupo alemán logro determinar el efecto viricida en concentraciones al 1\% sobre MERS-CoV y SARS-CoV 1(30). Por otro lado, el grupo japones solo lo hizo en el virus de la influenza humana y SARS-CoV 1(31). Sumado a esto, otros estudios demostraron su efectividad en otras concentraciones contra otros virus como el ébola, influenza, MERS, SARS, H1N1, rotavirus, gripe aviar y porcina, sarampión, herpes, adenovirus, rinovirus, poliovirus, HIV y coxsakiev, entre otros ${ }^{32}$.

Radiación ultravioleta. El uso de la radiación ultravioleta en el manejo intrahospitalario para el control y prevención de infección en centros de atención médica se logra mediante el uso de luz ultravioleta con una alta intensidad, es decir, con una longitud de onda de 200 a $280 \mathrm{~nm}$, alcanzando así un potente efecto germicida que destruye el ARN y ADN de virus, bacterias y patógenos que se puedan multiplicar. Es necesario conocer cómo es emitido este tipo de radiación y su espectro de desinfección; tenemos la luz ultravioleta de xenón pulsado que logra su efecto germicida a una longitud de onda de 200 a $320 \mathrm{~nm}$, este actúa también en superficies por lo que también funciona en las superficies lisas y brillantes de habitaciones hospitalarias. También existen elementos con mercurio ultravioleta C, usado en bombillas de mercurio a baja presión que emite un espectro de $254 \mathrm{~nm}$, esto se usa contra bacterias y esporas generando su inactivación genética(33). La radiación ultravioleta tiene un efecto mutagénico, pues al ser absorbido por las bases del ARN y ADN ocasionan una fusión fotoquímica de dos pirimidinas adyacentes en dímeros covalentemente unidos que luego se transforman en bases que no se emparejan, evitando así la replicación(34).

Estudios actuales prueban que para la inactivación del coronavirus se necesita una longitud de onda de $254 \mathrm{~nm}$, pero esto podría ser menor dado 
que, por lo general, estos estudios se llevan a cabo in vitro sin considerar la capacidad de reabsorción de la luz de los materiales(35).

\section{CONCLUSIÓN}

Los odontólogos cumplen un rol importante para interrumpir la cadena de transmisión si se ejecuta la práctica odontológica de acuerdo con los protocolos de bioseguridad apropiados. Dentro de este, se recomienda el uso de las sustancias de desinfección sugeridas (alcohol, hipoclorito de sodio, glutaraldehído, formaldehído, cloruro de cetilpiridino, povidona yodada y radiación ultravioleta), ya que presentan evidencias científicas de actividad viricida confiable para la desinfección de instrumental odontológico, así como para superficies que se contaminen en la consulta dental. De ese modo, se pretende reducir al máximo el riesgo de contaminación cruzada, el contagio entre el personal de atención odontológica y el paciente.

\section{PARTICIPACIÓN DE AUTORES}

AAC: Concepción y diseño del trabajo. Recolección de datos. Redacción del manuscrito. Aprobación del documento final; CBY: Concepción y diseño del trabajo. Recolección de datos. Redacción del manuscrito. Aprobación del documento final; MAM-V: Redacción y revisión crítica del manuscrito. Aprobación del documento final.

\section{FINANCIAMIENTO}

El trabajo fue autofinanciado.

\section{CONFLICTO DE INTERESES}

Los autores declaran no tener ningún conflicto de interés

\section{REFERENCIAS BIBLIOGRÁFICAS}

1. Phan T. Genetic diversity and evolution of SARS-CoV-2. Infect Genet Evol. 2020;81:104260.

2. World Health Organization. Coronavirus disease (COVID-19) pandemic [Internet]. Geneva: World Health Organization; 2021 [Acceso 03 de junio de 2021]. Disponible en: https://www.who.int/emergencies/diseases/novel-coronavirus-2019 
3. Matos-Alviso LJ, Reyes-Gómez U, Comas-García A, Luévanos-Velásquez A, Reyes-Hernández KL, Guerrero-Becerra $\mathrm{M}$, et al. Infecciones por coronavirus y el nuevo COVID-19: conceptos básicos. Rev Sal Jal. 2020;7(1):9-14.

4. Moreno M, Silva L, Ramos P, Ávila I, Vázquez M, Vicent G, et al. Odontología en entorno COVID-19. Adaptación de las unidades de salud bucodental en los centros de salud de la comunidad de Madrid. Rev Esp Salud Pública. 2020;94.

5. Pérez M, Gómez J, Dieguez R. Características clínico-epidemiológicas de la COVID-19. Rev Haban Cienc Méd. 2020;19(2):e3254.

6. Aguilar V, Febres V. Actitud ante la COVID-19 en la práctica dental rutinaria. Rev Ciencias Médicas. 2020;24(3):e4463.

7. Hamed MA. Una visión general sobre COVID-19: realidad y expectativa. Bull Natl Res Cent. 2020 junio;44:86.

8. Palacios Cruz M, Santos E, Velázquez Cervantes MA, León Juárez M. COVID-19, a worldwide public health emergency. Rev Clin Esp. 2020 Mar 20;221(1):55-61. Disponible en: https://doi.org/10.1016/j.rce.2020.03.001.

9. Contini C, Di Nuzzo M, Barp N, Bonazza A, De Giorgio R, Tognon M, et al. The novel zoonotic COVID-19 pandemic: An expected global health concern. J Infect Dev Ctries. 2020;14(3):254-264. Disponible en: https://doi.org/10.3855/jidc.12671

10. Diomedi A, Chacón E, Delpiano L et al. Antisépticos y desinfectantes: apuntando al uso racional. Recomendaciones del comité consultivo de infecciones asociadas a la atención de salud, sociedad chilena de infectología. Rev Chil Infectol. 2017;34(2):156-174. Disponible en: https://doi.org/10.4067/S0716-10182017000200010.

11. Talavera I, Menéndez A. Una explicación desde la química: ¿por qué son efectivos el agua y jabón, el hipoclorito de sodio y el alcohol para prevenir el contagio con la COVID-19? Anales de la Academia de Ciencias de Cuba [Internet]. 2020 [Acceso 15 de enero 2021]; 10(2):[aprox. 0 p.]. Disponible en: http://www.revistaccuba.sld.cu/index.php/revacc/article/view/781

12. Kampf G, Todt D, Pfaender S, Steinmann E. Persistence of coronaviruses on inanimate surfaces and their inactivation with biocidal agents. J Hosp Infect. 2020;104(3):246-251. Disponible en: 10.1016/j.jhin.2020.01.022.

13. Sánchez F, Furuya A, Arroniz P, et al. Comparación de la acción bactericida de hipoclorito de sodio y microcyn 60. Rev Odont Mex. 2009;13(1):9-16.

14. Sacoto A. Protocolos de bioseguridad en odontología frente a COVID-19 [Internet]. 2020 [Acceso 13 de enero de 2021]. Disponible en: http://repositorio.ug.edu.ec/handle/redug/49680 
15. Spicciarelli V, Marruganti C, Viviano M, Baldini N, Franciosi G, Tortoriello $\mathrm{M}$, et al. Prevention and safety in the dental office after novel human coronavirus outbreak: unresolved questions and future directions. J Osseointegr. 2020;12(2):145-153. Disponible en: https://doi.org/10.23805 /J0.2020.12.01.11

16. Silva Almerón JV, Veliz Duarte YJ. Eficacia del glutaraldehído al 2\% frente al proceso de desinfección de alto nivel. Tesis [Internet]. [Acceso $13 \mathrm{de}$ enero de 2021]. [Lima]: Facultad de Ciencias de la Salud, Universidad Privada Norbert Wiener; 2018. Disponible en: http://repositorio.uwiener.edu.pe/bitstream/handle/123456789/2373 /ESPECIALIDAD\%20-\%20SILVA\%20\%20VELIZ.pdf?sequence=1\&isAllowed=y

17. Bizzoca ME, Campisi G, Lo Muzio L. COVID-19 pandemic: what changes for dentists and oral medicine experts? a narrative review and novel approaches to infection containment. International Journal of Environmental Research and Public Health. 2020;17(11):37-93. Disponible en: https://doi.org/10.3390/ijerph17113793

18. Chemical Safety Facts. Formaldehído [Internet]. Washington DC: American Chemistry Council; 2021 [Acceso 13 de enero de 2021]. Disponible en: https://www.chemicalsafetyfacts.org/es/formaldehido/

19. Parra E, Zapata J. El formol. Su génesis, normas, aplicaciones e incidencia sobre la salud humana. Med UPB. 1999;18(1):35-45.

20. López M, Ramis G, Pallarés FJ. Puesta a punto de una técnica inmunohistoquímica frente al virus influenza porcino. An Vet (Murcia). 2017;33:105.

21. González L. Antisépticos y desinfectantes. Offarm. 2003;22(3):64-70.

22. Figuero E, Herrera D, Tobias A, Serrano J, Roldan S, Escribano M, et al. Efficacy of adjunctive anti-plaque chemical agents in managing gingivitis: a systematic review and network metaanalyses. J Clin Periodontol. 2019; 46(7):723-739.

23. Herrera D, Roldan S, Santacruz I, Santos S, Masdevall M, Sanz M. Differences in antimicrobial activity of four commercial $0.12 \%$ chlorhexidine mouthrinse formulations: an in vitro contact test and salivary bacterial counts study. J Clin Periodontol. 2003;30(4):307-314.

24. Roldan S, Winkel EG, Herrera D, Sanz M, Van Winkelhoff AJ. The effects of a new mouthrinse containing chlorhexidine, cetylpyridinium chloride and zinc lactate on the microflora of oral halitosis patients: a dual-centre, double-blind placebo-controlled study. J Clin Periodontol. 2003;30(5):427-434.

25. China National Health Commission. Chinese Clinical Guidance for COVID19 Pneumonia Diagnosis and Treatment. 7th ed. Beijing, China: China 
National Health Commission; 2020 [Acceso 4 de mayo 2020]. Disponible en: http://kjfy.meetingchina.org/msite/news/show/cn/3337.htm

26. Escribano M, Herrera D, Morante S, Teughels W, Quirynen M, Sanz M. Efficacy of a low-concentration chlorhexidine mouth rinse in noncompliant periodontitis patients attending a sup- portive periodontal care programme: a randomized clinical trial. J Clin Periodontol. 2010;37(3):266-275.

27. Herrera D, Serrano J, Roldán S, Sanz M. Is the oral cavity relevant in sarscov-2 pandemic? Clin Oral Investig. 2020;24(8):2925-2930.

28. Ren YF, Rasubala L, Malmstrom H, Eliav E. Dental care and oral health under the clouds of COVID-19. JDR Clin Trans Res. 2020;5(3):202-210.

29. Addy M, Wright R. Comparison of the in vivo and in vitro antibacterial properties of providone iodine and chlorhexidine glu- conate mouthrinses. J Clin Periodontol. 1978;5(3):198-205.

30. Eggers M, Koburger-Janssen T, Ward LS, Newby C, Muller S. Bactericidal and virucidal activity of povidone-iodine and chlorhexidine gluconate cleansers in an in vivo hand hygiene clinical simulation study. Infect Dis Ther. 2018;7(2):235-247.

31. Eggers M, Koburger-Janssen T, Eickmann M, Zorn J. In vitro bactericidal and virucidal efficacy of povidone-iodine gargle/mouthwash against respiratory and oral tract pathogens. Infect Dis Ther. 2018;7(2):249-259.

32. Costa X, Laguna E, Herrera D, Serrano J, Alonso B, Sanz M. Efficacy of a new mouth rinse formulation based on $0.07 \%$ cetylpyridinium chloride in the control of plaque and gingivitis: a 6-month randomized clinical trial. J Clin Periodontol. 2013;40(11):1007-1015.

33. Health Quality Ontario. Portable ultraviolet light surfacedisinfecting devices for prevention of hospital-acquired infections: a health technology assessment. Ont Health Technol Assess Ser. 2018;18(1):1-73.

34. Darnell ME, Subbarao K, Feinstone SM, Taylor DR. Inactivation of the coronavirus that induces severe acute respiratory syndrome, SARS-CoV. J Virol Methods. 2004;121(1):85-91.

35. Heßling M, Hönes K, Vatter P, Lingenfelder C. Ultraviolet irradiation doses for coronavirus inactivation - review and analysis of coronavirus photoinactivation studies. GMS Hyg Infect Control. 2020;15:Doc08. Disponible en: https://doi.org/10.3205/dgkh000343. 